\title{
A Review on the Reclamation Technologies for Service-Aged Transformer Insulating Oils
}

\author{
Sharin Ab Ghani*1, Zulkarnain Ahmad Noorden², Nor Asiah Muhamad³ ${ }^{3}$ Hidayat Zainuddin', \\ Mohd Aizam Talib ${ }^{5}$ \\ ${ }^{1,2}$ Institute of High Voltage and High Current (IVAT), Universiti Teknologi Malaysia, 81310 Johor Bahru, Malaysia \\ ${ }^{3}$ School of Electrical and Electronic Engineering, Engineering Campus, Universiti Sains Malaysia, 14300 Nibong Tebal, \\ Penang, Malaysia \\ ${ }^{1,4}$ Faculty of Electrical Engineering, Universiti Teknikal Malaysia Melaka, 76100 Durian Tunggal, Melaka, Malaysia \\ ${ }^{5}$ TNB Research Sdn. Bhd., No. 1, Lorong Air Hitam, Kawasan Institusi Penyelidikan, Kajang, Selangor, Malaysia.
}

\begin{tabular}{l}
\hline Article Info \\
\hline Article history: \\
Received Nov 9, 2017 \\
Revised Jan 28, 2018 \\
Accepted Feb 19, 2018 \\
\hline
\end{tabular}

Keywords:

Adsorbents

Condition monitoring

Reclamation

Transformer Oils

\begin{abstract}
Power transformers are the backbone of electricity transmission and distribution systems throughout the world. The price of power transformers is exorbitant (costing millions of dollars per unit) and therefore, frequent maintenance is necessary to ensure that these systems are highly reliable during their operation. The service life of mineral insulating oils is typically 30 to 40 years for power transformer applications. However, all insulating oils (regardless of their type) are subjected to thermal, electrical and chemical degradation, which will deteriorate the oil-paper insulating system and consequently reduce the capability of the oil as an electrical insulator. For these reasons, service-aged insulating oils are treated by two types of processes (i.e. reclamation and reconditioning) in order to prolong the service life of these oils. Reclamation (regeneration) is used to treat insulating oils with high levels of acidity and sludge. In this paper, a brief review on the reclamation technologies used to treat service-aged insulating oils is presented, covering various aspects such as the standard test methods that need to be complied with, the types of adsorbents used to reduce acidity and sludge of the used insulating oils, as well as the findings of several key studies related to the evaluation of the effectiveness of the reclamation process. This review will indeed benefit researchers and practitioners in this field since it provides an overall picture of the recent progress in reclamation technologies for service-aged transformer insulating oils.
\end{abstract}

Copyright $@ 2018$ Institute of Advanced Engineering and Science. All rights reserved.

\section{Corresponding Author:}

Sharin Ab Ghani

Institute of High Voltage and High Current (IVAT),

Universiti Teknologi Malaysia,

81310 Johor Bahru, Malaysia.

Email: sharinag@utem.edu.my

\section{INTRODUCTION}

One of the challenges in high voltage engineering is to minimize energy losses in power transformers, especially in high load conditions. The heat generated within the power transformer is a result of energy losses, which leads to degradation, premature aging and failure of components. This heat can be dissipated by circulating a certain liquid (i.e. insulating oil) from the hotter to the lower temperature region in order to minimize energy losses from the power transformer. This is illustrated in Figure 1, which shows the flow of the insulating oil within the cooling system of a typical power transformer. According to the "Transformer Oil Handbook" [1], a relatively high temperature range of $120-180^{\circ} \mathrm{C}$ leads to insulating failure due to the formation of gas bubbles whereas a temperature of $98^{\circ} \mathrm{C}$ results in aging of the insulating. 
It is essential for insulating oils to have excellent dielectric properties in order to prevent electrical contact between the energized conductors in power transformers. Insulating oils play a significant role in power transformers since these oils protect solid insulatings such as Kraft paper and pressboards, as well as quench arc discharges [2]. In addition, insulating oils serve as a heat dissipation and acoustic dampening medium. Power equipment operators are also able to gauge the condition of the power transformer based on the condition of the insulating oil [3]-[5].

Power transformers are subjected to various stresses in service as a result of high operating temperatures (especially at the hot spots which leads to pyrolysis), electric fields, vibrations from the magnetic core, oxygen (which leads to oxidation), moisture (which leads to hydrolysis), and other contaminants [6]. Each aspect of the power transformer is analyzed, tested and examined during the different stages of product design and development to ensure that the power transformer operates smoothly throughout its service life. However, in reality, the mechanical and dielectric properties of various components in the power transformer will degrade gradually over time. This degradation process occurs due to chemical reactions that take place when the power transformer is in operation, which are further aggravated by the presence of heat, oxygen and moisture. Moisture is harmful to the insulating paper since it initiates hydrolysis and cellulose chain scission. At the same time, oxygen reacts with the insulating oil (with metals and moisture as catalysts), producing a range of oxidation by-products, soluble or insoluble acids, and other polar substances [7]-[10]. These degradation products will affect the oil-paper insulating system in the long term, which will lead to severe degradation. According to Ward [10], [11], almost $75 \%$ of extra high voltage (EHV) power transformer failures resulting from dielectric breakdowns can be reduced by periodic maintenance including reclamation and reconditioning of insulating oils. In fact, reclaiming insulating oils extends the remaining useful life (RUL) of the power transformer by retarding the aging process of the insulating paper and pressboard.

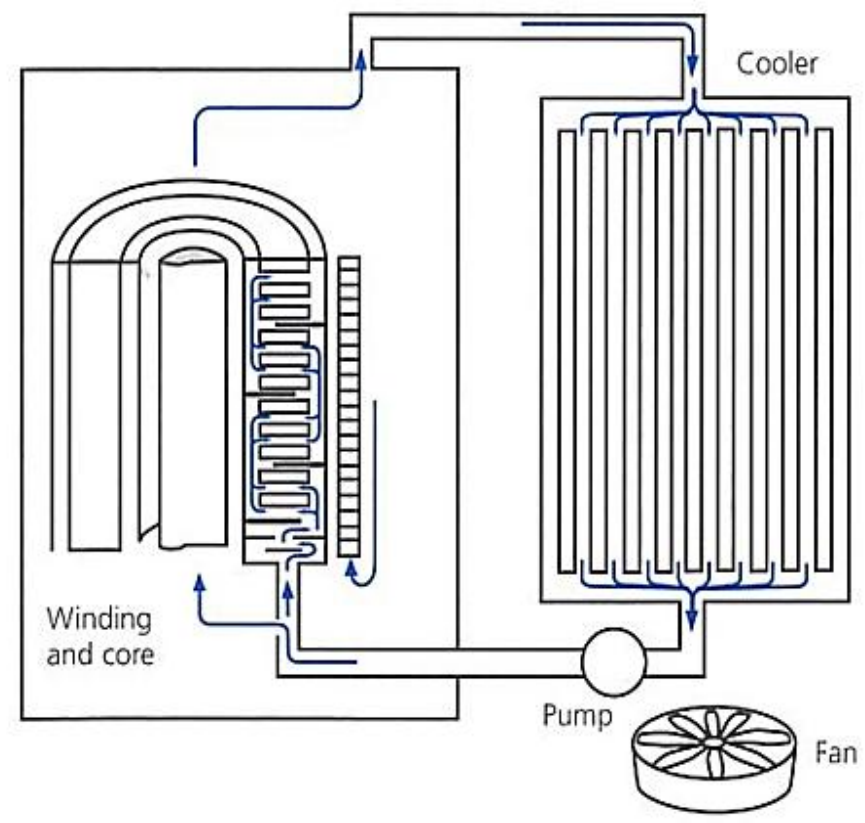

Figure 1. Flow of Insulating Oil Within the Cooling System of a Typical Power Transformer [1]. 

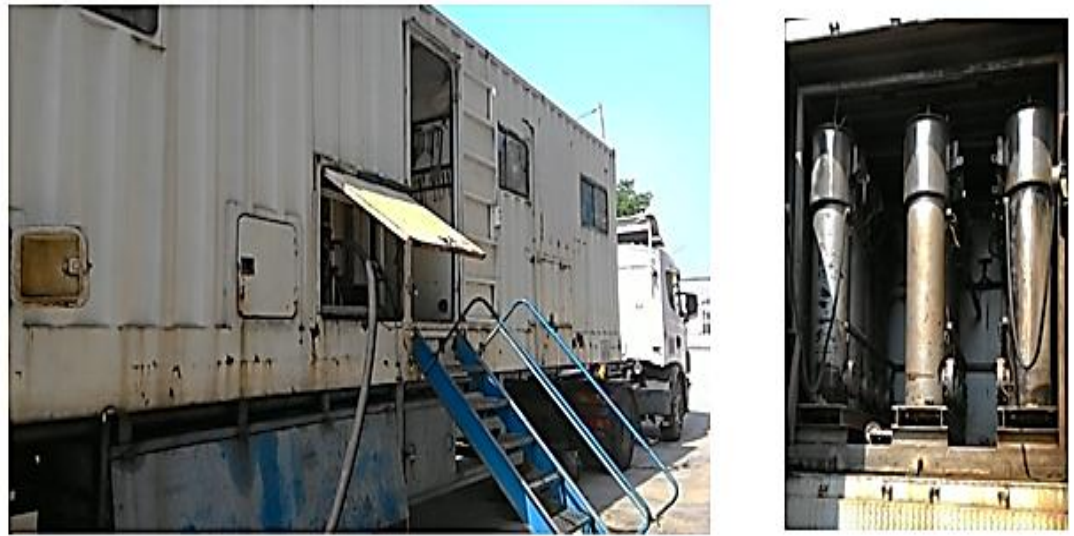

Figure 2. Online Mobile Insulating Oil Reclamation Plant: (left) Mobile Truck; (right) Column Tanks Filled with Adsorbent.

Reclamation of insulating oils by means of adsorbent beds has been widely implemented for almost 30 years [12], [13]. In practice, there are two types of operating modes for the reclamation process (i.e. offline and online), as shown in

Figure 2, respectively. At present, there are two standards that need to be complied with for reclamation of insulating oils, namely: (1) IEEE Std 637-1985 (R2007) (i.e. IEEE guide for the reclamation of insulating oil and criteria for its use), and (2) BS EN 60422:2013 (i.e. Mineral insulating oils in electrical equipment - Supervision and maintenance guidance). A comprehensive treatment on the operation, test methods, and properties of reclaimed insulating oils is given in both of these standards [14], [15]. At present, there are four types of adsorbents used in the reclamation process, namely: (1) Fuller's Earth (clay-based), bentonite (clay-based), activated alumina (aluminium hydroxide) and activated carbon (carbon-based). All of these adsorbents share one common purpose, which is to scavenge the oxidation by-products in the insulating oil [10], [16]-[23]. Fuller's Earth adsorbent is commonly used by maintenance service providers to reclaim service-aged insulating oils. However, there is a serious need to explore new types of adsorbents in order to enhance the reclamation process since this will extend the service life of insulating oils, which supports the notion of a greener environment. In general, these alternative adsorbents should be cost-effective, easy to acquire (in other words, the adsorbents can be manufactured locally), and able to be reactivated after use. More importantly, these alternative adsorbents should boost the speed of the reclamation process in order to minimize the outage period when the power transformer undergoes periodic maintenance [11], [16], [24][28] (

Figure 3).

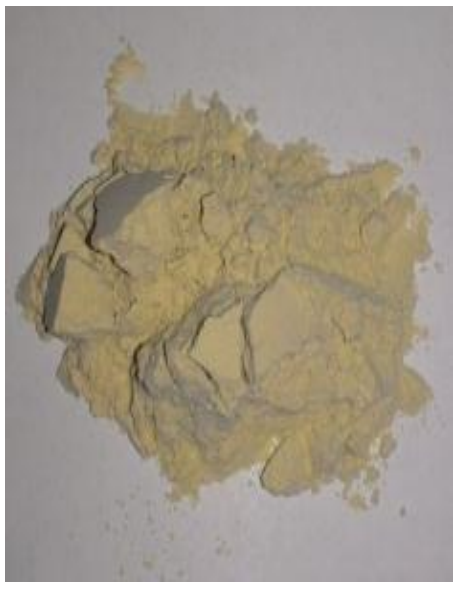

(a)

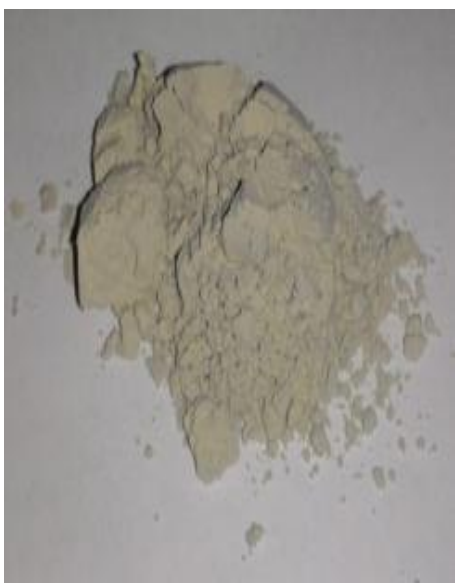

(b)

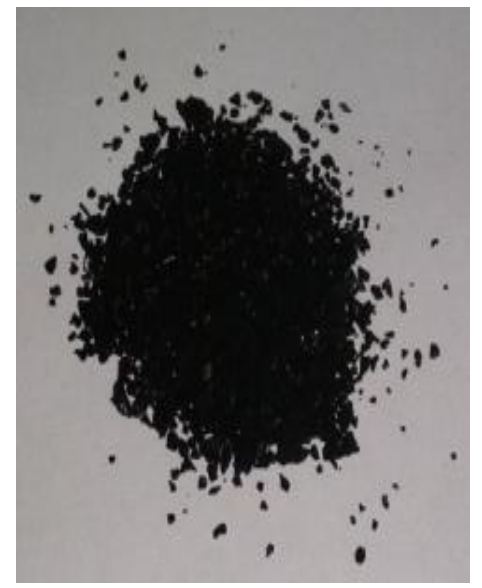

(c)

Figure 3. Photographs of the Adsorbents Used in the Reclamation of Used Transformer Oils: (a) Fuller's Earth, (b) Bentonite and (c) Palm Shell Activated Carbon [26]. 


\section{RECLAMATION OF INSULATING OILS}

In general, service-aged insulating oils are treated by three different processes: (1) reclamation, (2) re-refining, and (3) reconditioning. Since this review is focused on reclamation technologies for service-aged transformer insulating oils, the scope of the discussion is limited to the reclamation process. Based on the definitions given in [12] and [13], reclamation is "the restoration to usefulness by the removal of contaminants and products of degradation such as polar, acidic, or colloidal materials from used electrical insulating liquids". At present, there are two standards that need to be complied with regarding reclamation of insulating oils, namely: (1) IEEE Std 637-1985 (R2007) (i.e. IEEE guide for the reclamation of insulating oil and criteria for its use), and (2) BS EN 60422:2013 (i.e. Mineral insulating oils in electrical equipment Supervision and maintenance guidance). Both of these standards provide a comprehensive guide on the reclaiming procedure, the test methods used to assess the reclamation process, as well as the criteria that need to be fulfilled to ensure that the reclaimed oils can be used in oil-immersed power transformers $[12,13]$. Reclaiming service-aged insulating oils is not a task for novice power equipment operators since it requires a high level of technical competency and considerable experience. In addition, the properties of the reclaimed insulating oil needs to be assessed in order to determine the effectiveness of the reclamation process as well as estimate the RUL of the insulating oil. The reclamation process restores the properties of the service-aged insulating oil to a level that is comparable with the properties of unused mineral insulating oils specified in the IEC 60296 and ASTM D3487 standards. Reclaiming service-aged oils with moderate to high acidity typically yields oils with lower oxidation resistance compared with new oils. It is recommended that a laboratory feasibility test is carried out prior to the reclamation process. There are two types of reclamation process, namely: (1) reclamation by percolation, and (2) reclamation by contact [15], [20], [21].

\subsection{Reclamation By Percolation}

In this process, the insulating oil is collected from the bottom of the electrical equipment, and heated to a specific temperature. The insulating oil is circulated through a filter in order to eliminate solids and suspended particles, and the oil is delivered back to the top of the electrical equipment. The insulating oil is then circulated through one or more cartridges containing Fuller's Earth (or any other suitable adsorbents) in order to remove soluble polar contaminants. Lastly, the insulating oil is circulated through a reconditioning device (i.e. vacuum dehydrator or centrifuge) in order to remove moisture and gasses. There are two types of percolation techniques currently available, namely: (1) percolation by gravity, and (2) percolation by pressure. The latter technique (i.e. percolation by pressure) can be further divided into four types, namely, percolation using: (1) bulk filters, (2) deep bed filtration, (3) throw-away and repackable cartridges, and (4) thermo-siphon bypass.

Figure 4 shows the schematic diagram of percolation by gravity and percolation by pressure using various clay bulk filters.

\subsection{Reclamation By Contact}

In this process, the contaminated insulating oil is stirred in a suitable container, and Fuller's Earth is used as the adsorbent. This process is impractical for industrial applications since it requires very long outage periods for the electrical equipment. However, this process is useful to recycle large amounts of waste oils. Reclamation by contact is typically conducted on a laboratory scale in order to investigate the feasibility of the reclamation process for given oil as well as estimate the resultant properties of the oil that can be attained if reclamation is conducted on site (

Figure 5). 


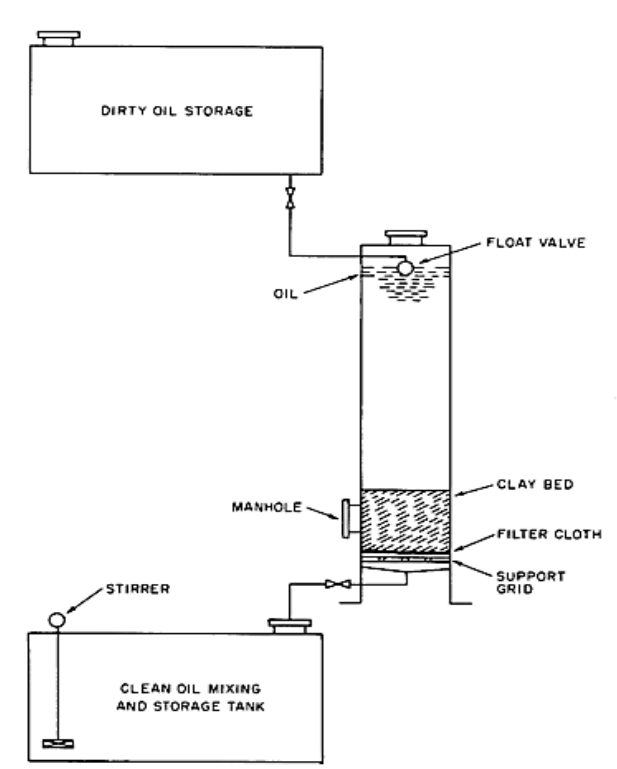

(a)
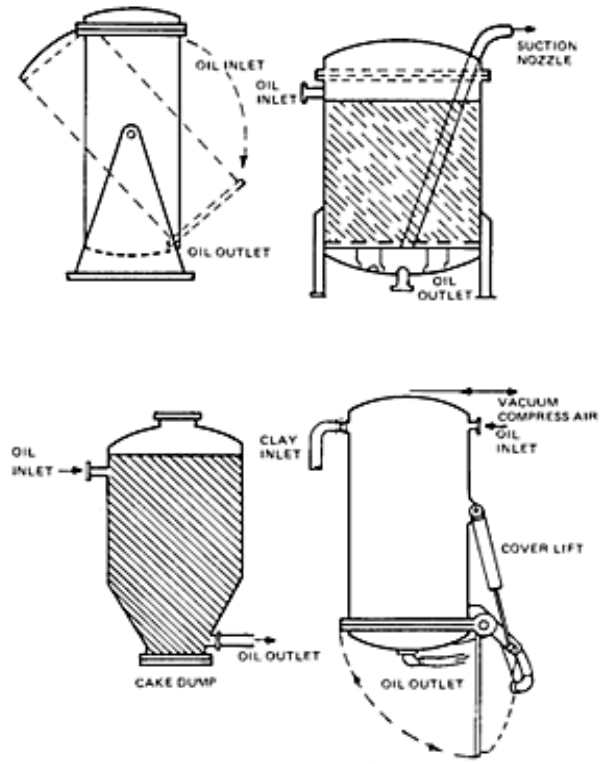

(b)

Figure 4. Schematic Diagram of Reclamation by Percolation: (a) Percolation by Gravity; (b) Percolation by Pressure Using Various Bulk Clay Filters [14].

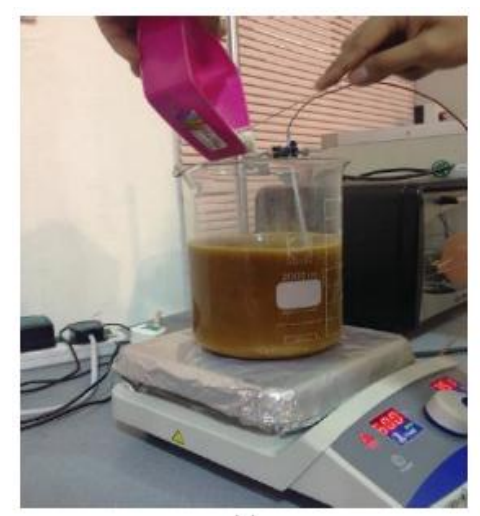

(a)

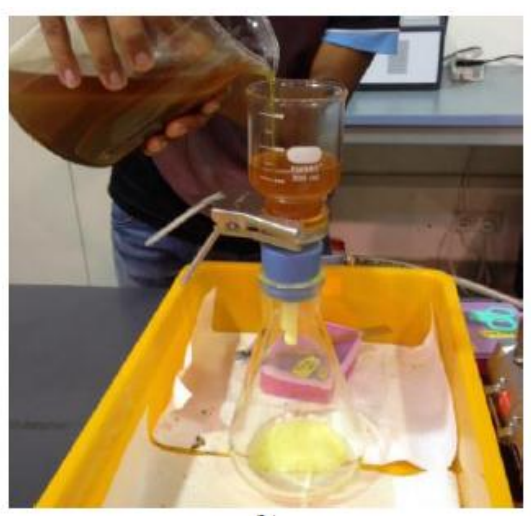

(b)

Figure 5. Process of Reclamation by Contact: (a) Mechanical Agitation of the Adsorbent in the Oil by Using Hotplate Magnetic Stirrer; (b) Filtering the Oil by Using Vacuum Filtration Flask [29].

\section{ADSORBENTS}

Adsorption is a process where one substance attracts and holds another substance tenaciously to its surface area. In general, most of the contaminants in the insulating oil (including water) are polar in nature and therefore, these contaminants are easily adsorbed. The contaminants present in the insulating oil can be removed using a suitable adsorbent. Fuller's Earth is a class of adsorbent clays existing in nature, rather than a specific mineralogical species [11], [14], which is commonly used in reclamation of service-aged insulating oils. Fuller's Earth is an active material that contains internal and external polar active sites, which allows the non-polar components of the insulating oil to pass through without retention while simultaneously retains the polar contaminants or degradation compounds dissolved in the oil [11], [17], [18]. There are a few types of clay available, though the ones that are widely used as adsorbents are sepiolite, bentonite, attapulgite, and montmorillonite. Fuller's Earth is most commonly used for reclamation process among all of these clays. Fuller's Earth is composed of silicate anions $\left(\mathrm{Si}_{2} \mathrm{O}_{5}\right)_{\mathrm{n}}$ condensed with octahedral layers of the type $\mathrm{X}(\mathrm{OH})$, where $\mathrm{X}$ may be magnesium, aluminum, or other materials. This mined product is then dried and processed 
by acid activation. Fuller's Earth is typically supplied as a fine powder, in which the colour may be gray, buff, green, brown or blue. Fuller's Earth is able to remove moisture, neutralize carboxylic acids, and adsorb polar contaminants. Moreover, Fuller's Earth improves discoloration, resulting in a clear insulating oil [14], [17], [18], [22]. However, bentonite is a promising low-cost adsorbent that is used extensively to remove toxic metal ions from wastewater [16], [24], [25]. Bentonite predominantly consists of smectite, which is a 2:1 clay mineral containing an octahedral sheet sandwiched between two tetrahedral sheets. The adsorption properties of bentonite are directly influenced by their montmorillonite content and interlayer cations. Bentonite has also been modified with acid in order to remove impurities and various exchangeable cations [16].

\section{EVALUATION OF THE EFFECTIVENESS OF RECLAMATION PROCESS}

In general, the reclamation process enhances the physical, chemical and electrical properties of the insulating oil. The neutralization number, interfacial tension, moisture content, turbidity, viscosity, flash point, fire point, AC breakdown voltage, dielectric dissipation factor (

Figure 6), polarization and depolarization current (

Figure 7), and absorbance curves using ultraviolet-visible spectroscopy (UV-Vis) in

Figure 8 and fourier transform infrared spectroscopy (FT-IR) in

Figure 9 are among the properties examined by many researchers to evaluate the effectiveness of the reclamation process.

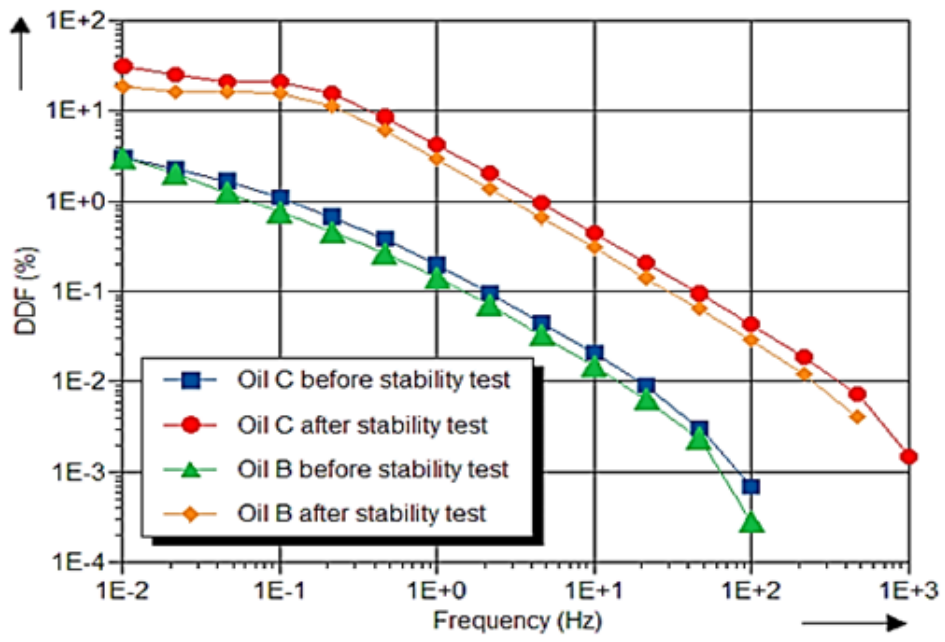

Figure 6. Frequency Scans of the Loss Factor for New and Reclaimed Transformer Insulating Oils After 15 Passes [11].
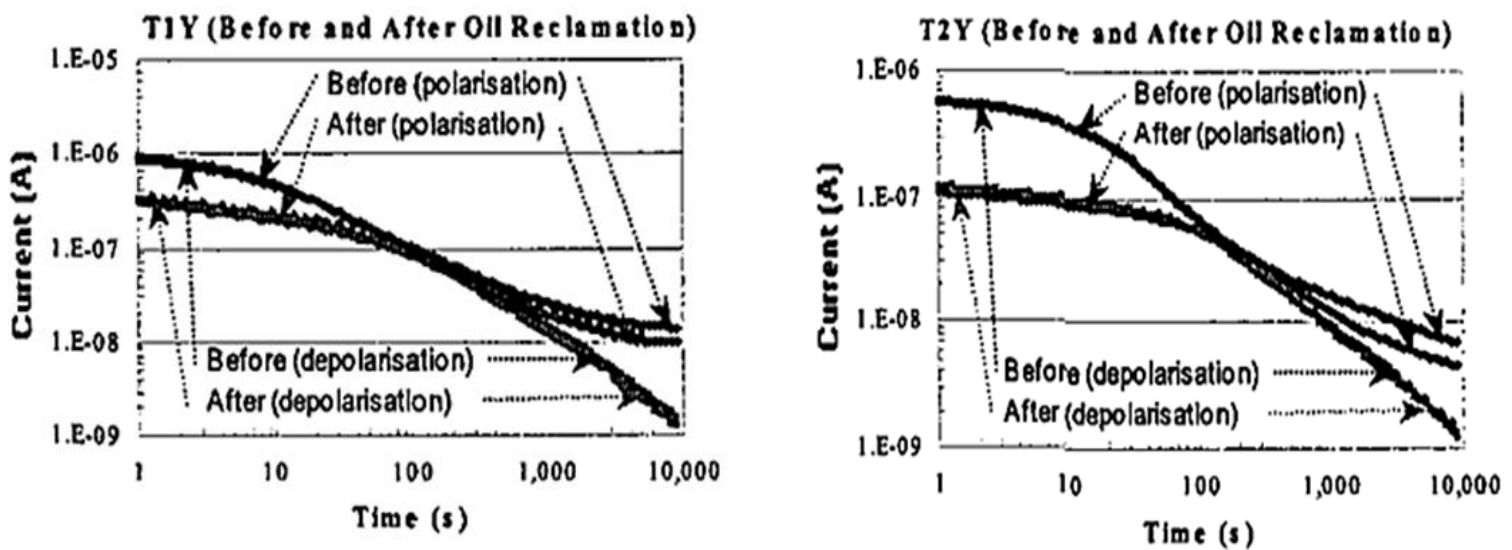
Figure 7. Measured Polarization and Depolarization Current (PDC) of 2 in-Service Transformer (T1Y and T2Y) Insulating Oil Before and After the Reclamation Process [30].

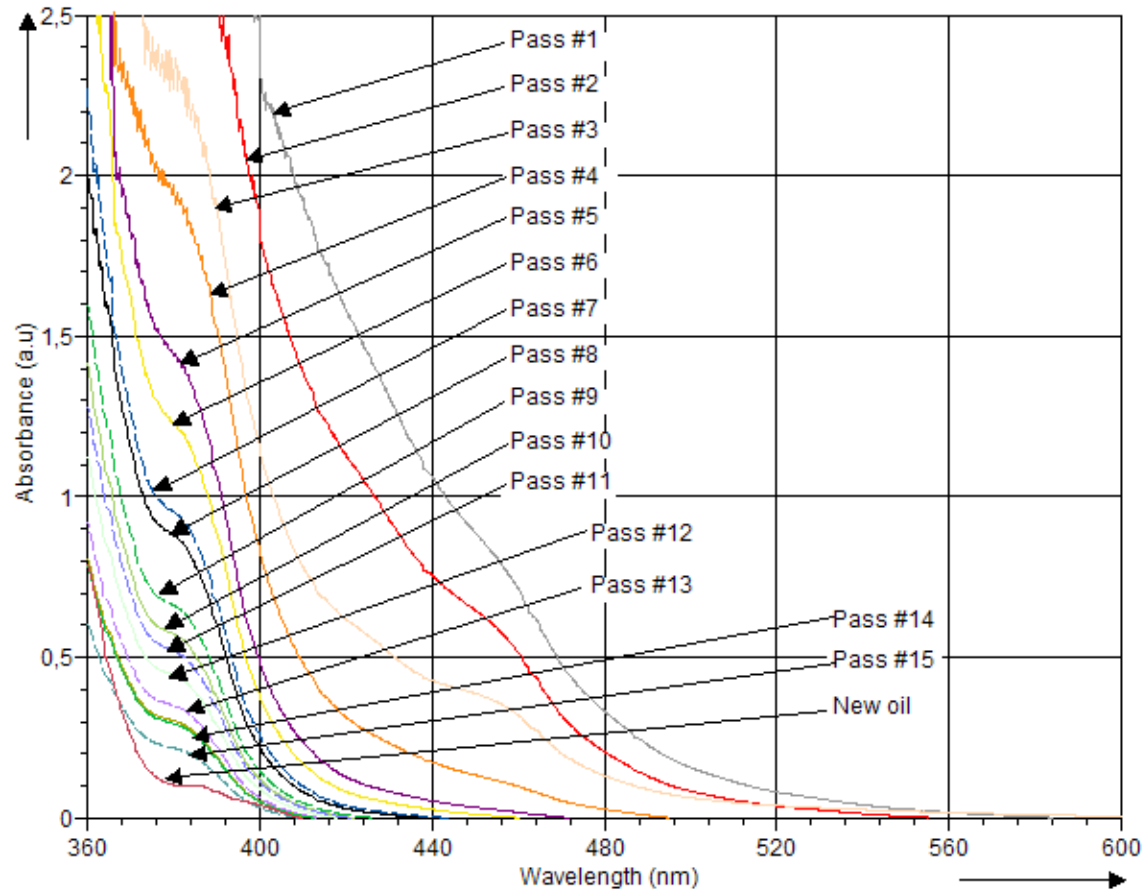

Figure 8. Absorbance Curves of UV-Vis Illustrating the Effect of Reclamation Passes on Oil Quality [11], [31].

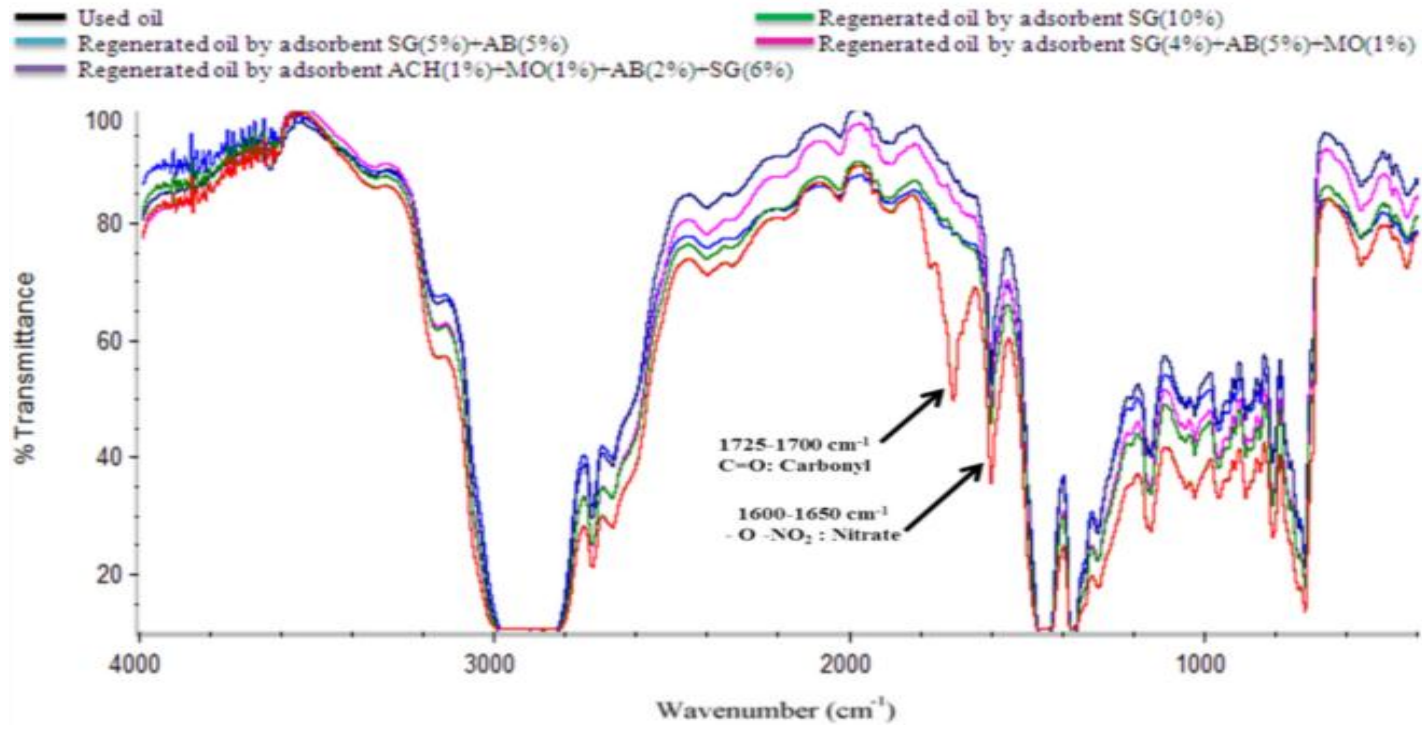

Figure 9. FT-IR Spectra of Service-Aged Insulating Oil Reclaimed with Mixtures of Adsorbents [28].

\section{CONCLUSION}

A brief review on the reclamation technologies for service-aged transformer insulating oils is presented in this paper. It is known that in-service insulating oils will degrade over time due to oxidation, resulting in unfavorable physical, chemical and electrical properties of the oils. For this reason, reclamation is used to treat service-aged insulating oils, and restore the properties of these oils to a level that is comparable to the properties of unused oils. Reclamation prolongs the service life of used insulating oils, which helps 
minimize wastes since the oils can be used over an extended period, rather than being disposed into the landfill. In addition, reclaimed transformer insulating oils extend the life expectancy of power transformers since these oils decelerate the aging process of the insulating paper and pressboard in oil-paper insulating systems. Reclamation of insulating oils by means of adsorbent beds has been widely implemented for almost 30 years. Since most of the contaminants in service-aged insulating oils are polar in nature, these contaminants can be easily adsorbed (and thus, removed) using a suitable adsorbent. At present, Fuller's Earth is the adsorbent most commonly used in the reclamation process since it is able to remove moisture, neutralize carboxylic acids, and adsorb polar contaminants, resulting in translucent insulating oil with favorable properties. However, Fuller's Earth can only be used once, and therefore, it must be disposed into the landfill after use. Hence, there is a need to explore alternative adsorbents that are more cost-effective, easy to acquire (whereby these adsorbents can be manufactured locally in Malaysia), and can be reactivated after use. More importantly, these alternative adsorbents should expedite the reclamation process, which will in turn, reduce the outage period when the power equipment undergoes periodic maintenance. This is indeed an interesting area for future research.

\section{ACKNOWLEDGEMENTS}

The authors graciously acknowledge the financial support provided by the Ministry of Higher Education Malaysia (MOHE), Universiti Teknologi Malaysia (UTM), and Universiti Teknikal Malaysia Melaka (UTeM) under the following grants: UTM (Q.J130000.2523.18H04) and UTeM (FRGS/1/2017/TK04/FKE-CERIA/F00332).

\section{REFERENCES}

[1] Transformer oil handbook, First Edit. Sweden: Nynas Naphtenis AB, 2004.

[2] N. A. Othman, H. Zainuddin, A. Aman, S. A. Ghani, and I. S. Chairul, "The correlation between surface tracking and partial discharge characteristics on pressboard surface immersed in MIDEL en," Int. J. Electr. Comput. Eng., vol. 7, no. 2, pp. 631-640, 2017.

[3] I. Fofana, "50 years in the development of insulating liquids," IEEE Electr. Insul. Mag., vol. 29, no. 5, pp. 13-25, Sep. 2013.

[4] R. Sanghi, "Chemistry behind the life of a transformer," Resonance, vol. 8, no. 6, pp. 17-23, Jun. 2003.

[5] H. De Faria, J. G. S. Costa, and J. L. M. Olivas, "A review of monitoring methods for predictive maintenance of electric power transformers based on dissolved gas analysis," Renew. Sustain. Energy Rev., vol. 46, pp. 201-209, Jun. 2015.

[6] M. A. Talib, N. A. Muhamad, Z. A. Malek, and B. T. Phung, "Fault identification of in-service power transformer using depolarization current analysis," Int. J. Electr. Comput. Eng., vol. 7, no. 2, pp. 559-567, 2017.

[7] I. Fofana, J. Sabau, D. Bussieres, and E. B. Robertson, "The mechanism of gassing in power transformers," in 2008 IEEE International Conference on Dielectric Liquids, 2008, pp. 1-4.

[8] I. Fofana, A. Bouaicha, M. Farzaneh, and J. Sabau, "Ageing Behaviour of Mineral Oil and Ester Liquids: a Comparative Study,” in 2008 Annual Report Conference on Electrical Insulation and Dielectric Phenomena, 2008, pp. 87-90.

[9] I. Fofana, A. Bouaicha, Y. Hadjadj, J. S. N'Cho, T. Aka-Ngnui, and A. Beroual, "Early stage detection of insulating oil decaying," in 2010 Annual Report Conference on Electrical Insulation and Dielectic Phenomena, 2010, pp. 1-4.

[10] B. Ward, “Application of Filtration System for On-Line Oil Reclamation, Degassing, and Dehydration,” EPRI Rep. 1002046, 2003.

[11] J. S. N'cho, I. Fofana, A. Beroual, T. Aka-Ngnui, and J. Sabau, "Aged oils reclamation: Facts and arguments based on laboratory studies," IEEE Trans. Dielectr. Electr. Insul., vol. 19, no. 5, pp. 1583-1592, Oct. 2012.

[12] S. D. Myers, J. Kelly, R. H. Parrish, and E. L. Raab, A guide to Transformer Maintenance. S. D. Myers Inc. Publishers, 1981.

[13] J. J. Kelly and D. P. Myers, "Transformer life extension through proper reinhibiting and preservation of the oil insulation," IEEE Trans. Ind. Appl., vol. 31, no. 1, pp. 55-60, 1995.

[14] ANSI/IEEE, "IEEE Std 637-1985 (R2007) IEEE Guide for the Reclamation of Insulating Oil and Criteria for Its Use," New York, USA, 2008.

[15] British Standards Institution, "BS EN 60422:2013 Mineral insulating oils in electrical equipment — Supervision and maintenance guidance," no. December. 2013.

[16] A. Raymon and R. Karthik, "Reclaiming aged transformer oil with activated bentonite and enhancing reclaimed and fresh transformer oils with antioxidants," IEEE Trans. Dielectr. Electr. Insul., vol. 22, no. 1, pp. 548-555, Feb. 2015.

[17] A. C. M. Silva, M. C. Guimarães Albuquerque, C. L. Cavalcante, T. N. Castro Dantas, and M. A. Santos Araujo, "Reclamation of Used Transformer Oil by Adsorption," Tribol. Trans., vol. 46, no. 2, pp. 223-227, Jan. 2003.

[18] H. M. Wilhelm, G. B. Stocco, and S. G. Batista, "Reclaiming of in-service natural ester-based insulating fluids," IEEE Trans. Dielectr. Electr. Insul., vol. 20, no. 1, pp. 128-134, Feb. 2013. 
[19] J. Wada, G. Ueta, S. Okabe, and T. Amimoto, "Techniques to inhibit transformer insulating oil degradation Effectiveness evaluation of the removal of degradation products using adsorbents," IEEE Trans. Dielectr. Electr. Insul., vol. 20, no. 6, pp. 2307-2316, Dec. 2013.

[20] K. O. Berg, K. Herdlevar, M. Dahlund, A. D. Renström, and U. Thiess, "Experiences From on-Site Transformer Oil Reclaiming," in CIGRE Paris Conference Paper 12-103, 2002.

[21] M. Dahlund, P. Koestinger, P. Meyer, and P. Khanna, "Life Extension of Power Transformers Oil Regeneration, On Site Drying and Onsite Repair," in PdMSA Conference, 2010.

[22] J. Sabau, "On line reclamation of aged transformer oils," in Proceedings: Electrical Insulation Conference and Electrical Manufacturing and Coil Winding Conference (Cat. No.01CH37264), 2001, pp. 557-565.

[23] L. G. M. Moura, "Recovery of used lubricant oils through adsorption of residues on solid surfaces," Brazilian J. Pet. Gas, pp. 091-102, Sep. 2010.

[24] L. Nasrat, M. Abdelwahab, and G. Ismail, "Improvement of Used Transformer Oils with Activated Bentonite," Engineering, vol. 3, no. 6, pp. 588-593, 2011.

[25] L. Nasrat and M. S. Hassan, "Effect of Bentonite on the Properties of Liquid Insulating Oil," Int. J. Chem. Mol. Nucl. Mater. Metall. Eng., vol. 6, no. 8, pp. 1089-1095, 2012.

[26] S. A. Ghani, N. A. Muhamad, and H. Zainuddin, "Performance of palm shell activated carbon as an alternative adsorbent for reclamation of used transformer oil," ARPN J. Eng. Appl. Sci., vol. 10, no. 22, pp. 10752-10758, 2015.

[27] A. I. Hafez, N. S. Gerges, H. N. Ibrahim, W. S. I. Abou El-magd, and A. I. Hashem, "Evaluation of kaolin clay as natural material for transformer oil treatment to reduce the impact of ageing on copper strip," Egypt. J. Pet., vol. 26, no. 2, pp. 533-539, 2017.

[28] L. Safiddine, A. Hadj-Ziane Zafour, I. Fofana, A. Skender, F. Guerbas, and A. Boucherit, "Transformer oil reclamation by combining several strategies enhanced by the use of four adsorbents," IET Gener. Transm. Distrib., vol. 11, no. 11, pp. 2912-2920, 2017.

[29] I. S. Chairul, S. A. Ghani, H. Zainuddin, N. H. Rahim, M. A. Talib, and N. H. Nor Rahman, "Exploration of the potential of reclaimed waste cooking oil for oil-immersed power transformers," Telkomnika (Telecommunication Comput. Electron. Control., vol. 15, no. 2, 2017.

[30] S. A. Bhumiwat and P. Phillips, "Verification of on-site oil reclamation process by means of polarisation/ depolarisation current analysis," in Conference Record of the 2004 IEEE International Symposium on Electrical Insulation, 2004, no. September, pp. 105-108.

[31] J. S. N'Cho, I. Fofana, A. Beroual, T. Aka-Ngnui, and J. Sabau, "The gassing tendency of reclaimed oils," in 2011 IEEE International Conference on Dielectric Liquids, 2011, pp. 1-4. 


\section{BIOGRAPHIES OF AUTHORS}

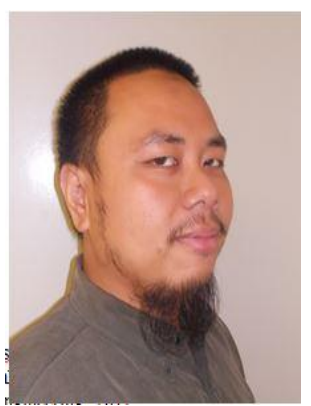

Sharin Ab Ghani received the BEng. (Hons) degree in Electrical Engineering from Universiti Teknikal Malaysia Melaka (UTeM) in 2008 and the MEng. Degree in Electrical Engineering from Universiti Tenaga Nasional, Malaysia (UNITEN) in 2012. He served as a lecturer at Universiti Teknikal Malaysia Melaka (UTeM). Currently, he is a PhD student at Universiti Teknologi Malaysia. His research interests are in electrical insulation, power equipments \& insulation condition monitoring, and renewable energy.

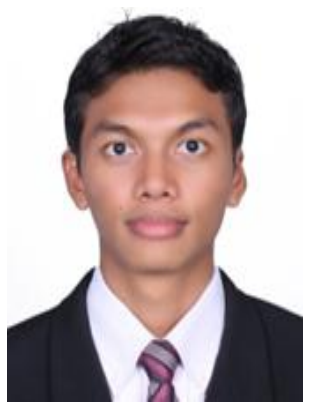

Zulkarnain Ahmad Noorden received the B.Eng. and M.Eng. degrees in electrical engineering from Universiti Teknologi Malaysia in 2008 and 2009, respectively. He joined the Faculty of Electrical Engineering as a Tutor in 2008 after completing the B.Eng. degree. In 2013, he completed his Ph.D. degree in Regional Environment System (Electrical Engineering) from Shibaura Institute of Technology, Tokyo, Japan. Currently, he is a Senior Lecturer at the Institute of High Voltage and High Current, Universiti Teknologi Malaysia. His research interests include ultra-capacitor materials and technology, energy storage systems, power equipment diagnosis, and high voltage generation.

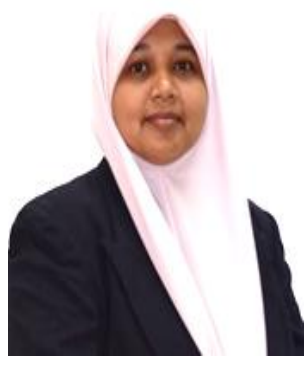

Nor Asiah Muhamad currently working as Senior Lecturer at the School of Electrical And Electronic, Universiti Sains Malaysia. Previously she was one of the researcher and senior lecturer at the Institute of High Voltage and High Current in the Faculty of Electrical Engineering, Universiti Teknologi Malaysia for 13 years. She finished her Ph.D. in 2009 at the University of New South Wales, Australia. She had earlier received a Bachelor's degree in electrical and electronic engineering from the Universiti Teknologi Petronas, Malaysia in 2002 and a Master's degree in electrical power engineering from The University of South Australia in 2006. Her research interest in power system equipment monitoring started in 2005 , and the main topics related to this interest are insulation diagnosis and new systems for condition monitoring.

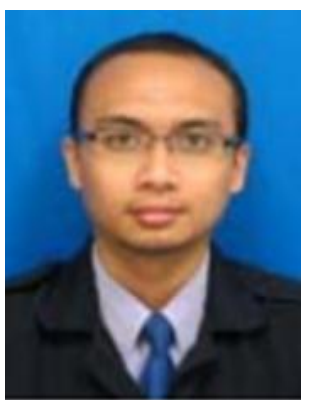

Hidayat Zainuddin received his Bachelor of Engineering in Electrical from the Universiti Teknologi Malaysia (UTM) in 2003. He obtained his MSc in Electrical Power Engineering with Business from the University of Strathclyde, Glasgow in 2005. He received his $\mathrm{PhD}$ degree at the University of Southampton, United Kindom in 2013. He has been as academic staff of the Universiti Teknikal Malaysia Melaka (UTeM) since 2003 and at present is the senior lecturer in Faculty of Electrical Engineering at the university. He is the Lab Head for the High Voltage Engineering Research Laboratory, Universiti Teknikal Malaysia Melaka (UTeM). His research interests include $\mathrm{HV}$ equipment and insulation condition monitoring, failure analysis, and power system protection coordination.

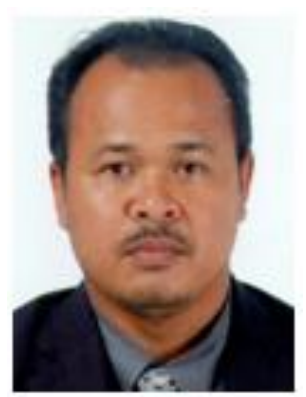

Mohd Aizam Talib has over 19 years of experiences in dealing with transformer diagnostic, condition and life assessment and failure analysis of power transformer. After graduated, he has worked with ABB Transmission and Distribution Sdn Bhd as Design Engineer and in 1998; he has joined TNB Research Sdn Bhd as Research Engineer. He has held several positions with TNB Research as Senior Researcher, Testing Engineer, Assistant Manager and Manager for High Voltage Testing Laboratory. He is currently holding a position as Technical Expert (Transformer) with TNB Research Sdn Bhd. He was previously a member of Malaysia National Working Group TC 42 for High Voltage Testing with SIRIM and currently active member with Malaysian National Committee of CIGRE, WG A2 Power Transformer. He has published and presented technical papers related to transformer diagnostic and condition assessment at national and international journal and conferences. 